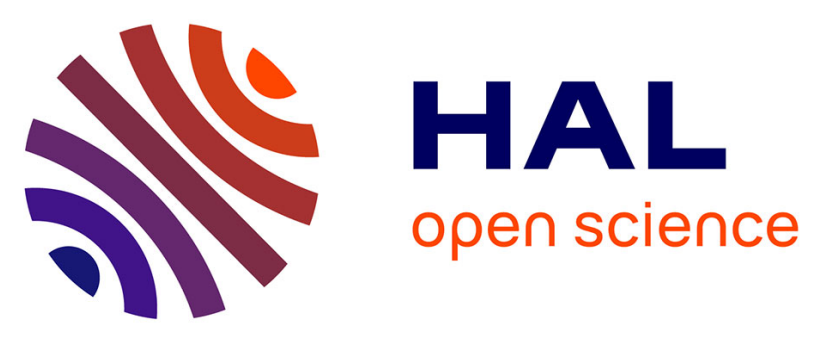

\title{
All solid-state ionic actuators based on polymeric ionic liquids and electronic conducting polymers
}

Frederic Braz Ribeiro, Cedric Plesse, Giao T.M. Nguyen, Sofia Morozova, Eric Drockenmuller, Alexander Shaplov, Frederic Vidal

\section{- To cite this version:}

Frederic Braz Ribeiro, Cedric Plesse, Giao T.M. Nguyen, Sofia Morozova, Eric Drockenmuller, et al. All solid-state ionic actuators based on polymeric ionic liquids and electronic conducting polymers. 9th International Conference on Electromechanically Active Polymer, EuroEAP 2021, Jun 2021, Linköping, Sweden. 10.1117/12.2300774 . hal-03258389

\section{HAL Id: hal-03258389 \\ https://hal.science/hal-03258389}

Submitted on 17 Sep 2021

HAL is a multi-disciplinary open access archive for the deposit and dissemination of scientific research documents, whether they are published or not. The documents may come from teaching and research institutions in France or abroad, or from public or private research centers.
L'archive ouverte pluridisciplinaire $\mathbf{H A L}$, est destinée au dépôt et à la diffusion de documents scientifiques de niveau recherche, publiés ou non, émanant des établissements d'enseignement et de recherche français ou étrangers, des laboratoires publics ou privés. 


\title{
All solid-state ionic actuators based on polymeric ionic liquids and electronic conducting polymers
}

\author{
Frederic B. Ribeiro*a ${ }^{\mathrm{a}}$, Cedric Plesse ${ }^{\mathrm{a}}$, Giao T.M. Nguyen ${ }^{\mathrm{a}}$, Sofia M. Morozova ${ }^{\mathrm{b}}$, \\ Eric Drockenmuller ${ }^{c}$, Alexander S. Shaplov ${ }^{b, d}$, Frederic Vidal ${ }^{a}$ \\ ${ }^{a}$ Laboratoire LPPI, EA 2528, Université de Cergy-Pontoise, Cergy, France \\ ${ }^{\mathrm{b}}$ A.N. INEOS RAS, Moscow, Russia \\ ${ }^{c}$ Laboratoire IMP, UMR CNRS 5223, Lyon, France \\ ${ }^{\mathrm{d}}$ LIST laboratory, Esch-sur-alzette, Luxembourg
}

\begin{abstract}
Ionic electro-active polymers (EAP) are promising materials for actuation and sensing. In order to operate in open-air, they are usually built in a trilayer configuration where the internal polymer membrane is soaked with an exogenous electrolyte and sandwiched between two electronic conducting polymer (ECP) layers.

The use of exogenous electrolytes can be a limitation in several applications since it may lead to evaporation issues and leakage. Moreover, the soaking step, necessary to introduce the electrolyte in the device, can become tricky as soon as microdevices are considered.

In this work we describe the synthesis and characterization of truly "all-solid-state" ionic actuators by using polymeric ionic liquids (PILs). PILs are a new class of polyelectrolytes presenting ionic liquid-like ions along their polymer backbone. First, ECP electrodes containing PIL are synthesized by vapor phase polymerization and their thickness and electronic conductivity are characterized. Then, electrodes and PIL-based membranes are assembled into a trilayer configuration as a proof of concept of solid-state ionic actuator. Under $1.75 \mathrm{~V}$, a strain difference about $1 \%$ is reached.
\end{abstract}

Keywords: ionic actuators, electronic conducting polymers, polypyrrole, polymeric ionic liquids

\section{INTRODUCTION}

Smart materials and structures based on electroactive polymers (EAPs) represent a fast growing and stimulating field of research and development. EAPs are materials capable of changing dimensions and/or shape in response to suitable electrical stimuli. Since many of these characteristics can also describe natural muscle tissues from an engineering point of view, it is not surprising that EAP transducers are sometimes also referred to as "artificial muscles" 1 .

In this field, electronic conducting polymers (ECPs) have attracted great attention, notably because they have some important advantages like low driving voltage and inherent electronic conductivity. Their volume changes are due to the insertion/expulsion of charge balancing ions occurring during the oxidation/reduction process of the ECP electrodes.

When the liquid electrolyte is incorporated into a polymer membrane and combined with two ECP electrodes into a trilayer configuration ${ }^{2,3}$, open-air actuation can be obtained. Under low voltage stimulation $(<2 \mathrm{~V})$ opposite redox processes are occurring in each electrode leading to opposite volume variations and then to an overall bending deformation of the device.

The central ionic conducting membrane, being usually either an electrolyte-soaked porous membrane or an electrolyteswollen polymer gel, plays a critical role. First, it acts as electrolyte reservoir to provide the ions necessary to the redox process of the ECP electrodes. Second, the overall response speed of the actuator, limited by diffusion of ions, is directly related to the ionic conductivity of the membrane. Finally, the membrane usually insures the mechanical robustness of such electrochemomechanical devices. 
Central membranes combining both high ionic conductivity and good mechanical properties have been already demonstrated by using soaked porous membranes (i.e. PVDF) ${ }^{4}$ or swollen-ones (i.e. gel or IPN) ${ }^{5,6}$ by ionic liquids and led to actuators with good performances, compatible with microsystem processes and presenting fast response speed $^{7,8,9,10}$. Nevertheless, the presence of an exogenous liquid electrolyte makes these materials considered as "wet" EAPs and despite the advantage offered by these ionic liquids-based actuators a risk of leakage during storage or operation cannot be excluded. Moreover, the introduction of liquid electrolyte, by swelling or soaking, can be time consuming and involves undesired handling step that can be tricky, especially as soon as microactuators are considered. Therefore, it is desirable to convert "wet" IL-based actuators into trully solid-state device.

Then, we propose here to use polymeric ionic liquids (PILs) as solid polymer electrolyte (SPE). Polymeric/polymerized ionic liquids or poly(ionic liquid)s (PILs) refer to a special type of polyelectrolytes which contains ionic liquid-like species which are covalently bonded to a polymer backbone ${ }^{11-16}$. On the opposite of classical polyelectrolytes requiring the presence of a solvent, PILs benefit from the fact that their ionic charges have chemical structures similar to the ones of ionic liquids allowing their dissociation and mobility without any additional solvent. Frequently, PILs contain cations such as imidazolium, pyrrolidinium, pyridinium, ammonium or phosphonium, which are either chemically bonded to the main polymer chain or presents as free counter ions. It is worth noting that although ILs are in a liquid state near room temperature, PILs are in fact solid in most cases, except a couple of exceptions ${ }^{17}$.

The major advantages of using a PIL instead of an IL are the enhanced mechanical stability, improved processability and durability over the IL species. Such chemical architecture allows combining all beneficial properties of ionic liquids with those of classical polyelectrolytes. They offer the unique possibility to develop truly all-solid-state electrochemical devices in many exciting technologies such as batteries, fuel cells, supercapacitors and electrochromic devices ${ }^{18-20,21,22}$. In this paper, we report first the synthesis and characterization of ECP+PIL-based electrodes by vapor phase polymerization (VPP). Then, these electrodes are assembled with a flexible PIL-based SPE membrane combining both ionic and mechanical properties. The resulting device is stimulated under an applied voltage of $1.75 \mathrm{~V}$ and a strain difference of $1 \%$ is reached demonstrating the proof of concept of a truly all-solid-state ionic actuator.

\section{EXPERIMENTAL SECTION}

\subsection{Materials}

Iron (III) p-toluene sulfonate $\left(\mathrm{Fe}\left(\mathrm{C}_{7} \mathrm{H}_{7} \mathrm{SO}_{3}\right)_{3} 55 \%\right.$ in n-butanol, Clevios C-B $54 \mathrm{~V} 3$, Heraeus), poly(ethylene glycol) methyl ether methacrylate (PEGM, Mn = $475 \mathrm{~g} \mathrm{~mol}^{-1}$ ), were used without further purification. Acetonitrile, ethanol and methanol were used as received. Pyrrole (Sigma - Aldrich) was distilled before use. The polyimide PIL (PI PIL), PILco-PEGM, and PIL C1 were synthesized as described elsewhere (being published) (Fig. 1).

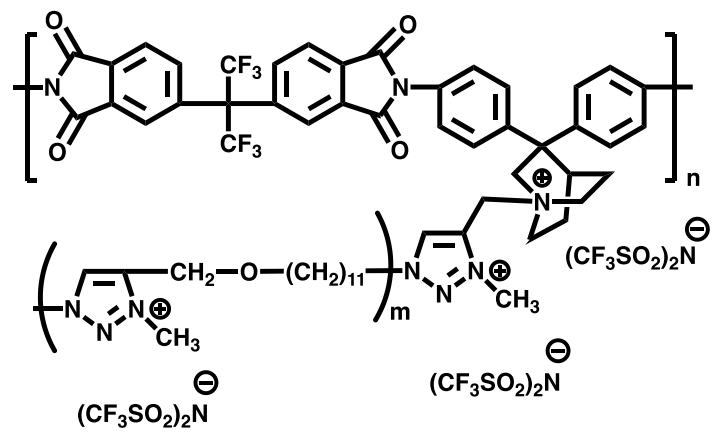

PI PIL
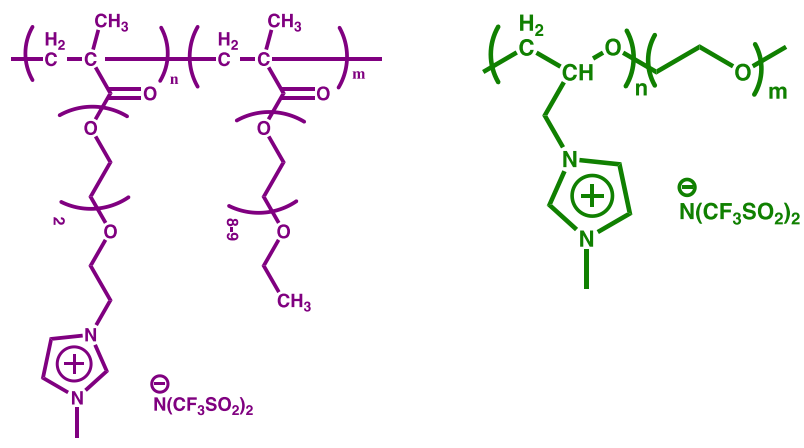

PIL-CO-PEGM
PIL C1

Figure 1 : Chemical formulas of PI PIL, PIL-co-PEGM and PIL C1 


\subsection{Preparation of the PI PIL-based SPE central membrane}

The central membrane of the actuator was prepared by casting a solution of the PI PIL by solubilizing it in tetramethylurea (TMU) (Fig. 2). For that, $0.15 \mathrm{~g}$ of PI PIL were solubilized in $9 \mathrm{~mL}$ of TMU for 5 days at $70{ }^{\circ} \mathrm{C}$, then the solution was evaporated in a teflon dish at $50^{\circ} \mathrm{C}$. Finally, to remove the remaining solvent, the film was dried under dynamic vacuum at $70{ }^{\circ} \mathrm{C}$ for several days. This method allowed to get films with thickness about $0.17 \mathrm{~mm}$. It should be underlined this PI PIL possesses both mechanical properties brought by its backbone chain (Figure 2, red) and ionic conductivity properties brought by its pending chains. Per pending chain, there is an average of 10 counter-ions. Its ionic conductivity has been measured at $1 \cdot 2 \cdot 10^{-5} \mathrm{~S} / \mathrm{cm}$ at $25^{\circ} \mathrm{C}$.

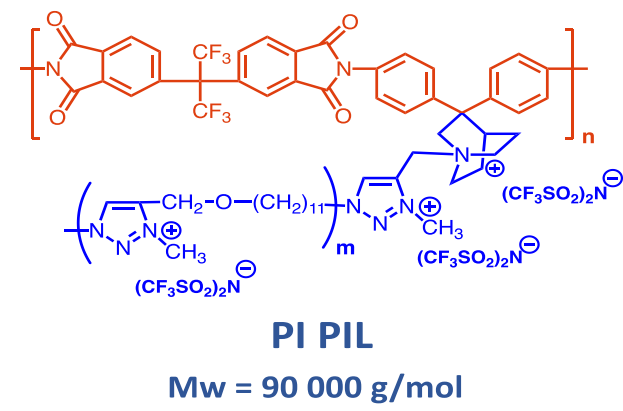

1. Solubilization in TMU

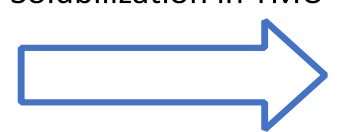

2. Polymer solution casting

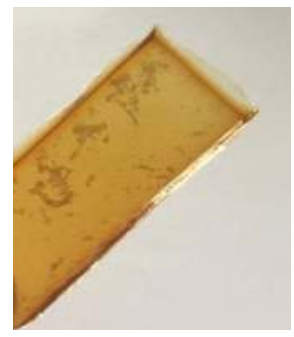

Figure 2: casting procedure of the polyimide polymeric ionic liquid (PI PIL)

\subsection{Synthesis of the electrodes}

Electrodes with PPy + PIL C1 were prepared through the following procedure (Fig. 3): $0.2 \mathrm{~g}$ of PIL C1 were solubilized in $1 \mathrm{~mL}$ of acetonitrile then stirred until complete solubilization. Then $0.1 \mathrm{~g}$ of PEGM and $0.7 \mathrm{~g}$ of oxidant (i.e. Iron (III) p-toluene sulfonate $55 \%$ in n-butanol) were added to it. Finally, the solution was filtered through a syringe with a porosity of $0.2 \mu \mathrm{m}$ to avoid the presence of dusts. This oxidant solution was spin-coated onto a glass substrate, dried 2 minutes on a hot plate at $60{ }^{\circ} \mathrm{C}$ to evaporate the solvent (i.e. butanol and acetonitrile). When the coating is almost dry, the Fe (III) tosylate starts to form crystals and the color of the coating changes to dark yellow indicating that the solvent is now evaporated. Then, the substrates were put under a vacuum bell in the presence of $2 \mathrm{~mL}$ of distilled pyrrole at 25 ${ }^{\circ} \mathrm{C}$ for $2 \mathrm{~h}$.

The vapor-phase polymerization (VPP) was carried out in a simple single-chamber under static vacuum with a heater which provides the possibility to control the temperature.

Once the electrodes were synthesized they have been dried for $1 \mathrm{~h}$ at room temperature until residual vapors had evaporated. Following the VPP, the samples were washed and lifted-off a couple of seconds in methanol and in warm deionized water at $45^{\circ} \mathrm{C}$ to remove unreacted monomers or oxidant as well as short oligomers and byproducts remaining after the polymerization ${ }^{23,24}$. 


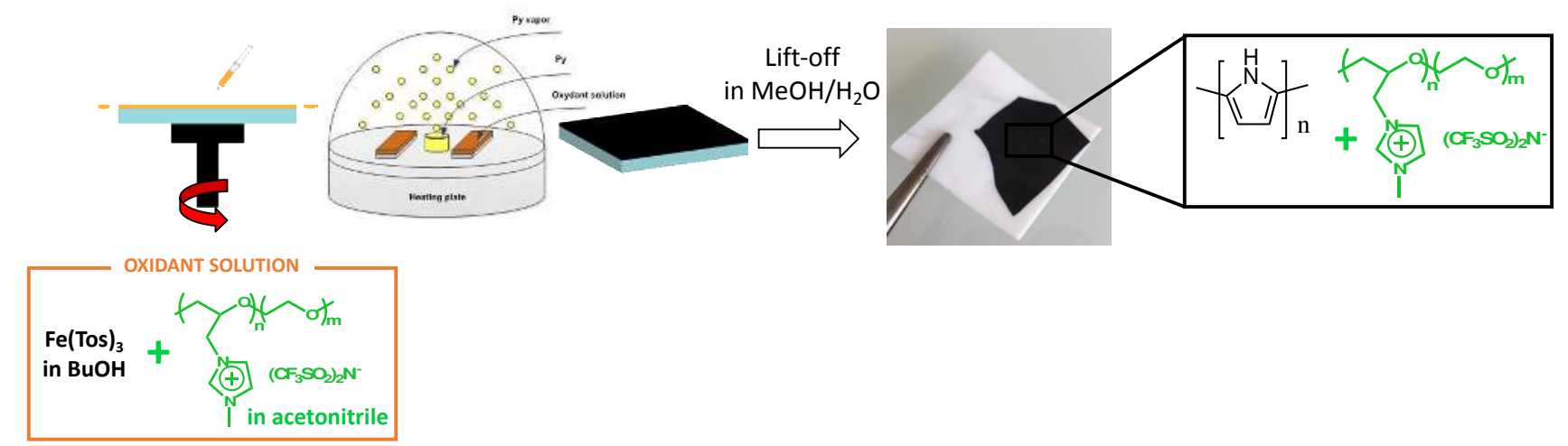

Figure 3: Synthesis route of the film electrodes made with PPy + PIL C1

\subsection{Synthesis of the actuators}

To make the trilayer actuators, $0.5 \mathrm{~mL}$ of a solution of $0.15 \mathrm{~g}$ of PIL-co-PEGM in $2 \mathrm{~mL}$ of acetone were sprayed in both sides of the PI PIL membrane by using an airbrush (volume flow of $120 \mathrm{Nl} / \mathrm{h}$ ). Since PIL-co-PEGM is very sticky it acts as an ionic conductive glue. Finally, electrodes of PPy + PIL C1 were stuck from each side of the central membrane (Fig. 4).
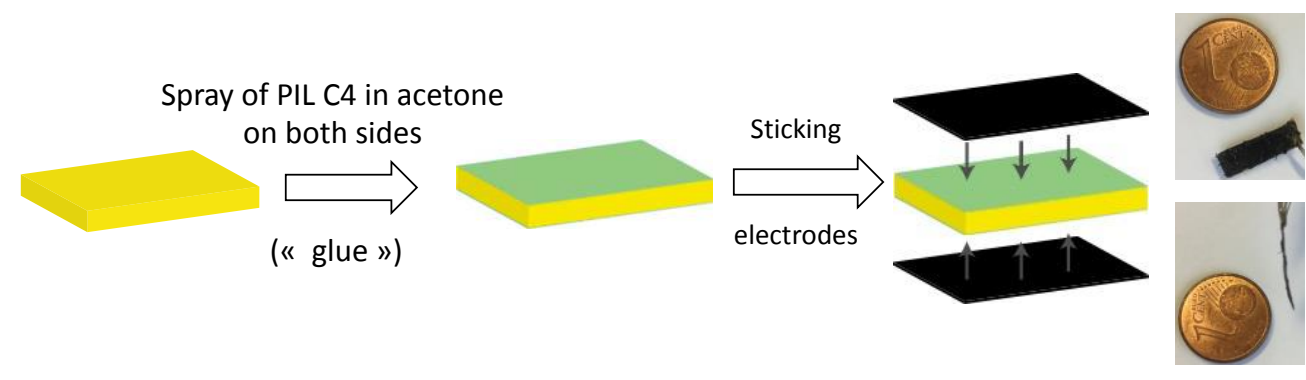

Figure 4: Schematic procedure to elaborate an all solid-state ionic actuator

\subsection{Characterizations}

The ionic conductivity of the polymeric ionic liquids was measured by electrochemical impedance spectroscopy using a VSP 150 potentiostat (Biologic SA). Samples of 1 x $1 \mathrm{~cm}$ were placed between two gold electrodes and a sinusoidal voltage $\mathrm{E}$ with a $2 \pi \mathrm{f}$ pulsation is applied. The resultant current is monitored and by plotting the imaginary part $-\mathrm{Im} \mathrm{Z}$ $(2 \pi f) v s$ the real part $\operatorname{Re} Z(2 \pi f)$ is then possible to determine the bulk resistance. The ionic conductivity was calculated by using the following formula: $\sigma(\mathrm{S} / \mathrm{cm})=(1 / \mathrm{Z})^{*}(\mathrm{l} / \mathrm{a})$ where $\mathrm{z}$ is the real part of impedance which is obtained by using the LCR bridge, 1 the thickness and a the area of the sample.

The film thickness was measured by a DekTak 150 profilometer (VEECO). The electronic conductivity of the polymer coatings was measured by using a four-point probe on $3 \times 3 \mathrm{~cm}$ substrates. During a measurement sequence, the current through the sample is changed from a low level where the potential drop over the sample is in the $\mu \mathrm{V}$ range to the current level where the potential is well above $10 \mathrm{mV}$. To eliminate errors from thermovoltages and voltmeter offsets, two current pulses of opposite signs are used for each measurement point.

To measure the actuation, beam films of 1 x $3 \mathrm{~cm}$ were maintained horizontally with steel clamps. The displacements were obtained by applying a voltage between $\pm 1.75 \mathrm{~V}$. The deformation of the film was recorded with a laser displacement sensor (ILD 1401-5, Micro-Epsilon) and from the resulting displacement signal, the strain difference between the two outer electrodes, $\varepsilon$, was calculated according to Sugino et al. formula ${ }^{25}$ :

$$
\varepsilon=\frac{2 D W}{L^{2}+D^{2}}
$$


where $\mathrm{D}$ is the half of the peak-to-peak displacement, $\mathrm{W}$ is the thickness of the actuator and $\mathrm{L}$ is the distance from the clamped beam to the projection of the laser spot.

\section{RESULTS AND DISCUSSIONS}

\subsection{Optimization of the film electrodes}

ECP electrodes were first synthesized and characterized separately (i.e. thickness and electronic conductivity) from the actuator. The vapor phase polymerization (VPP) method has been chosen to synthesize the electrodes since it is an efficient and easy technique to synthesize thin ECP layers with high electronic conductivity. ${ }^{26}$ It is expected also that this procedure will lead to sufficient electroactivity to consider the use of these electrodes in all-solid-state actuators. Beyond that, the electrodes should display also high ionic conductivity to allow efficient redox process during actuation. As a consequence, PIL have to be introduced also during the VPP synthesis of the electrodes. Then the resulting electroactive electrodes will be a composite of PPy and PIL C1.

Finally, since the electrodes will be finally glued on both sides of the central membrane in the final device they must be thick enough to be handled easily (i.e. thickness around $5 \mu \mathrm{m}$ ).

PIL C1 content effect. Since both of electronic and ionic conductivities in electrodes are necessary to get an actuation, PIL is introduced directly in the oxidant solution for the VPP of Py. The influence of PIL content on thickness and electronic conductivity of PPy + PIL C1 electrodes was investigated. These film electrodes were prepared by spincoating the oxidant solution in the presence of PIL C1 at $500 \mathrm{rpm}, 1200 \mathrm{rpm} / \mathrm{s}$ for $30 \mathrm{~s}$ and carrying the VPP at $25^{\circ} \mathrm{C}$ for $2 \mathrm{~h}$. Figure 5 shows the evolution of the final thickness and corresponding electronic conductivity of such electrodes regarding the PIL C1 content. First, when PIL C1 content in the oxidant solution is increasing the thickness of the electrode increases from 1.5 to $8 \mu \mathrm{m}$. This behavior can be explained by the increase of solid content in the final electrode and by the intrinsic viscosity of the PIL C1 which make the spin-coated oxidant solution thicker. At the same time, a decrease of electronic conductivity from 4.3 to $0.3 \mathrm{~S} / \mathrm{cm}$ is observed. This trend can be attributed by the increase of electronically insulating components in the electrode making it harder for the PPy chains to growth and to reach the percolation.

Finally, in order to have a compromise between ionic charge carriers in the electrodes, electronic conductivity and a sufficient film electrodes thickness, it has been chosen to incorporate $8 \%$ wt. of PIL C1 inside them.

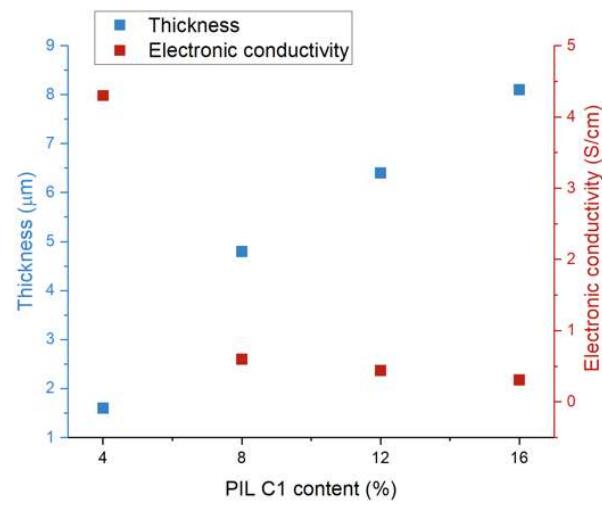

Figure 5: Evolution of the thickness and the electronic conductivity of 3 x $3 \mathrm{~cm}$ PPy + PIL-C1 electrodes regarding the PIL-C1 content 
Synthesis parameters effect. To reach an electronic conductivity as high as possible it has been decided to investigate and optimize the VPP synthesis conditions to assess their influence on the electrode electronic conductivity.

In that purpose, the properties (thickness and electronic conductivity) of the PPy + PIL C1 (8\% wt.) synthesized electrodes were studied as a function of the spin-coating speed (from 500 to $1500 \mathrm{rpm}$ ), the VPP duration (from 90 to $190 \mathrm{~min}$ ) and the VPP temperature (from 22 to $30^{\circ} \mathrm{C}$ ).

Fig. 6 summarizes the influence of all these parameters on the electronic conductivity of PPy + PIL C1 film electrodes. Regarding the influence of the spin-coating speed the electronic conductivity is a slightly decreasing from 1.2 to 0.4 $\mathrm{S} / \mathrm{cm}$ when the spin-coating speed increases from 500 to $800 \mathrm{rpm}$ and then remains constant around $0.4 \mathrm{~S} / \mathrm{cm}$ from 800 to $1500 \mathrm{rpm}$. Concomitantly, the thickness is also decreasing when the rotation speed is increasing, from $2.4 \mu \mathrm{m}$ to 1.5 $\mu \mathrm{m}$. Usually highest electronic conductivities are obtained for thin film (i.e. high rotation speeds) which is not the case here. This result seems to indicate that percolation of PPy chains in the ECP-PIL electrode requires sufficient final thickness of the film to occur and may indicate some 3D structural disorder ${ }^{27}$.
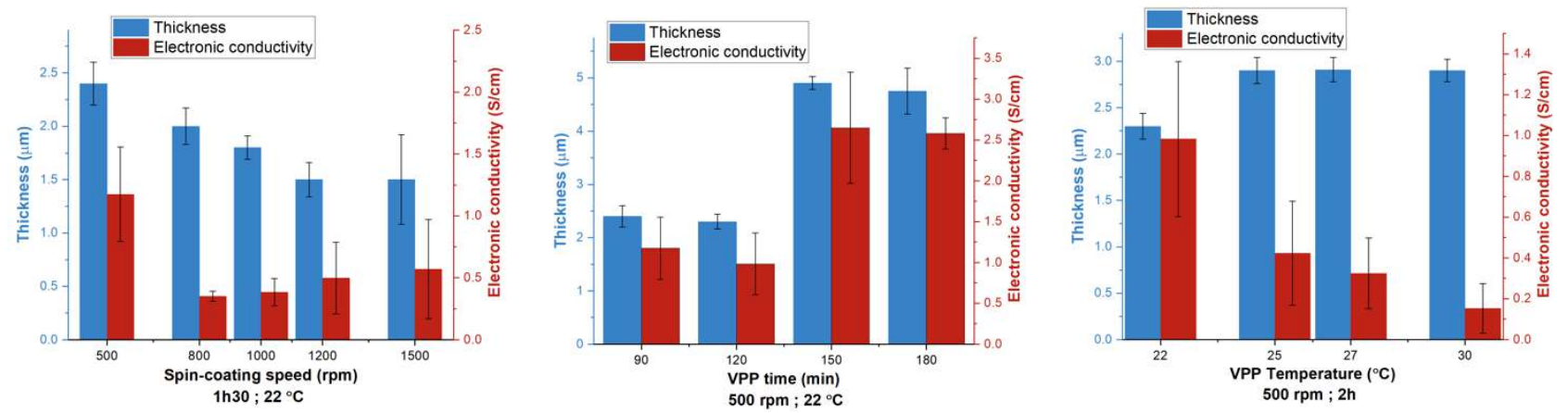

Figure 6: Influence of spin-coating speed, VPP duration and VPP temperature on the thickness and electronic conductivity of PPy $+8 \%$ wt. PIL C1 film electrodes

Thickness and electronic conductivity are slightly increasing as a function of VPP duration, from $2.5 \mu \mathrm{m}$ and $1 \mathrm{~S} / \mathrm{cm}$ (90 $\mathrm{min}$ ) to $5 \mu \mathrm{m}$ and $2.5 \mathrm{~S} / \mathrm{cm}$ (180 $\mathrm{min})$ respectively. Once again it seems that thickness and electronic conductivity are evolving with the same trend and that 3D percolation of PPy chains need sufficient thickness to occur. The polymerization need to be carried out at least during $120 \mathrm{~min}$ to reach a threshold time ${ }^{28}$. The plateau value obtained after 150 min suggest all oxidant has breacted and the polymeric chains do not grow anymore.

With the increase of the VPP temperature, final thickness of the electrodes is slightly increasing from $2.3 \mu \mathrm{m}\left(22^{\circ} \mathrm{C}\right)$ to $3 \mu \mathrm{m}\left(30^{\circ} \mathrm{C}\right)$ while the electronic conductivity is significantly decreasing, from 1 to $0.15 \mathrm{~S} / \mathrm{cm}$ respectively. It is worth mentioning that no film is obtained above $30^{\circ} \mathrm{C}$. This trend is opposite to the one observed for the two other parameters since electronic conductivity is here inversely proportional to the final thickness. Knowing that an increase of VPP temperature increases both polymerization kinetic constant and Py monomer vapor concentration, the increase of polymerization rate may result in a decrease of the molecular weight of PPy chains and an increase of the structural disorder.

Finally, by proper choice of synthesis conditions (i.e. $500 \mathrm{rpm}, 22{ }^{\circ} \mathrm{C}, 2 \mathrm{~h}$ ), it was possible to produce homogeneous and thick conductive PPy-PIL electrodes on glass substrates. The "optimized" conditions led to films with an electronic conductivity of $2.5 \mathrm{~S} / \mathrm{cm}$ and a thickness of $5 \mu \mathrm{m}$. Although this electronic conductivity value is much lower than values which can be obtained for polypyrrole electrodes made by vapor phase polymerization (up to $1000 \mathrm{~S} / \mathrm{cm}$ for nanometer thick films ${ }^{29}$ ) it should be underlined these films are much thicker and they contain a polymeric ionic liquid inside. Moreover, electronic conductivities between $10^{-6} \mathrm{~S} / \mathrm{cm}$ and $0.1 \mathrm{~S} / \mathrm{cm}$ were reported elsewhere for casted films made of an electronic conducting polymer (PPy, PANI or PEDOT) and a polymeric ionic liquid ${ }^{30}$. The values obtained here are then 25 times higher which prove that VPP polymerization in the presence of PILs is an asset for elaborating electrodes. 
In order to assess the electroactivity of these electrodes, the synthesis of PPy+PILC1 composite was carried out onto an ITO glass and resulting electrodes were washed in warm water and cold $\mathrm{MeOH}$ and finally cycled in an electrolyte $(0.5$ M LiTFSI in water). Figure 7 shows the cyclic voltammetry of such electrode between -0.9 and $+0.5 \mathrm{~V}$ vs Ag. A voltamogram with well-defined oxidation and reduction peaks at $+0.05 \mathrm{~V}$ and $-0.5 \mathrm{~V}$ respectively is obtained and indicates that such electrodes can efficiently undergo the redox processes necessary for actuation in the final device.

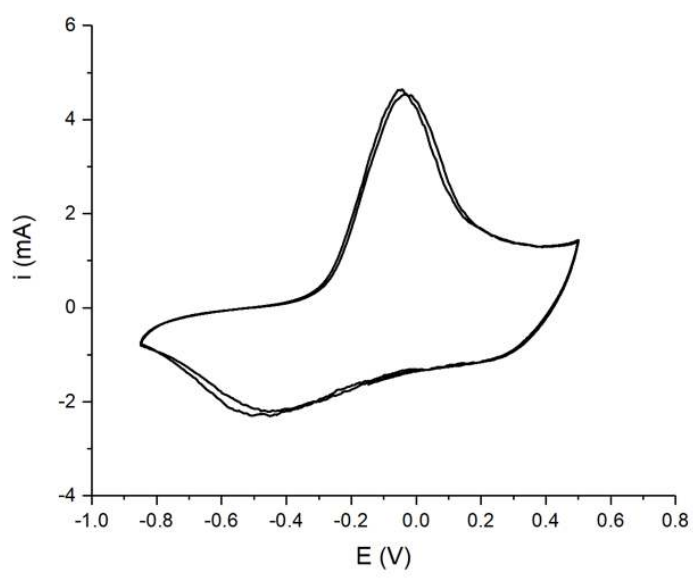

Figure 7: Cyclic voltammetry of PPy + PIL C1 electrodes in $0.5 \mathrm{M} \mathrm{LiTFSI}$ in water $50 \mathrm{mV} / \mathrm{s}$ at $25^{\circ} \mathrm{C}$

\subsection{Ionic conductivity of PILs}

The ionic conductivity of all PILs used in this study has been measured by electrochemical impedance spectroscopy (EIS). Figure 8 shows the ionic conductivity behavior versus the temperature of both PI PIL which has been used as central membrane, PIL C1 which was incorporated in the electrodes and PIL-co-PEGM. Since the copolymer PIL-coPEGM possesses both a high ionic conductivity and a very sticky behavior it has been chosen to use it as an "ionic conductive glue" to stick the electrodes on both sides of the central membrane in order to allow to counter-ions to move through all actuator layers (from one opposite electrode to the other one). It is worth to note regardless which PIL is used in the electrodes or to stick the electrodes to the central membrane since the counter-ion is the same over the thickness of the actuator (TFSI') no anion exchange will occur.

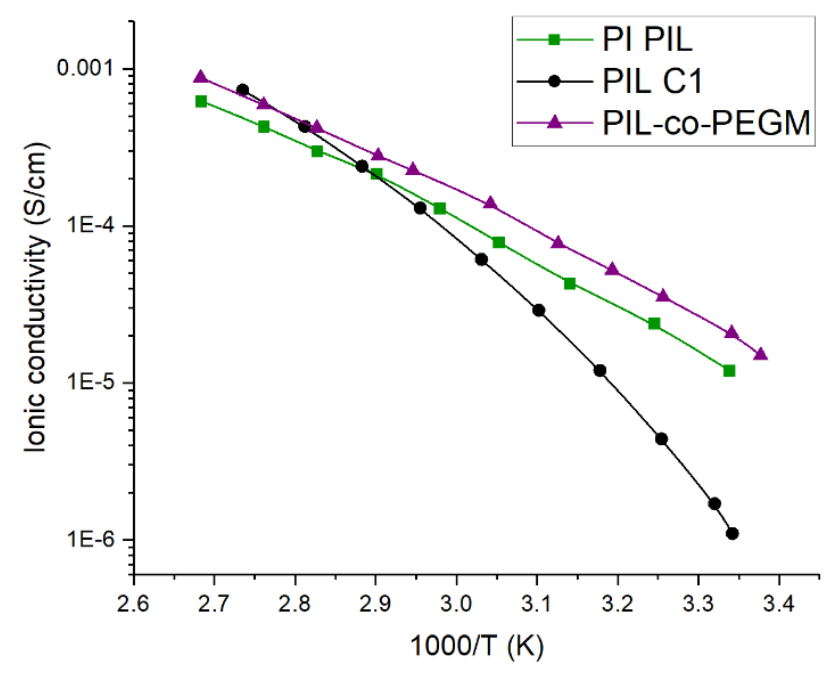

Figure 8: Ionic conductivity behavior of PI PIL, PIL C1 and PILco-PEGM measured by EIS regarding the temperature 
PI PIL and PIL-co-PEGM are the ones which possesses the highest ionic conductivities at room temperature, $1.2 .10^{-5}$ $\mathrm{S} / \mathrm{cm}$ and $1.5 .10^{-5} \mathrm{~S} / \mathrm{cm}$ at $25{ }^{\circ} \mathrm{C}$, respectively. PIL $\mathrm{C} 1$ is the one which possess the lowest ionic conductivity at $25{ }^{\circ} \mathrm{C}$ with $8.4 .10^{-7} \mathrm{~S} / \mathrm{cm}$. By increasing the temperature, the ionic conductivity increases as the mobility of the ions rises to finally reach nearly $10^{-3} \mathrm{~S} / \mathrm{cm}$ at $100^{\circ} \mathrm{C}$.

It should be underlined that PI PIL and PIL-co-PEGM possesses quite high ionic conductivities for PILs and all PILs have a sufficient ionic conductivity at room temperature to consider them in all-solid-state actuators.

\subsection{Actuation results}

The all-solid-state device was then assembled manually by pressing the PPy+PIL C1 electrodes on each face of a $170 \mu \mathrm{m}$ thick PIL PI membrane. To efficiently bond the electrodes, the ionically conducting glue PIL-co-PEGM was first sprayed on PIL PI membrane. The final structure of the solid-state actuator is then "PPy+PIL C1 electrode//PIL-coPEGM glue//PIL PI membrane//PIL-co-PEGM glue// PPY+PIL C1 electrode".

A square wave potential of $+/-1.75 \mathrm{~V}$ is then applied to the device and the resulting bending displacement is recorded with a laser displacement sensor. Typical time profile of the applied voltage and resulting free displacement and electrical current of the actuator are depicted in Fig. 9.

First it can be observed that during electrical stimulation a reversible bending movement is observed, demonstrating the feasibility of an all solid state ionic actuator. It is interesting to point out that bending occurs systematically toward the reduced electrode, i.e the volume of the electrode is decreasing during the reduction process. Indeed, charge compensation of the redox process can occur according to two mechanisms, i.e mobile anion et non-mobile anion mechanism ${ }^{31}$. In the case of mobile anion mechanism, oxidation/reduction of ECP chain will generate/remove positive charges along the polymer backbone and the electroneutrality will be insured by anions insertion/expulsion. The resulting volume change is then a volume expansion during oxidation and a volume contraction during reduction. In the case of this all solid-state actuator, free ion species in every layer, i.e. membrane, glue and electrodes, are TFSI $^{-}$anions. The direction of bending of the actuator is then consistent with the charge of the free ions and the mobile anion mechanism.

Mechanical response versus electrical stimulation is observed with the free strain varying from about $1 \%$ which is in the order of values obtained for ECP based ionic actuators ${ }^{32}$. The maximum displacement tends to a plateau after for 20 min and reflects a very slow electrochemical system which is the consequence of an all solid-state system.

It should be underlined that actuation tests with PEDOT:PSS electrodes which possess almost the same electronic conductivity of those PPy + PIL C1 electrodes (i.e $2 \mathrm{~S} / \mathrm{cm}$ ) but without PIL inside them were done and led to no actuation at all. It highlights the need of PIL inside the electrodes to insure the ionic continuity through all the sample.
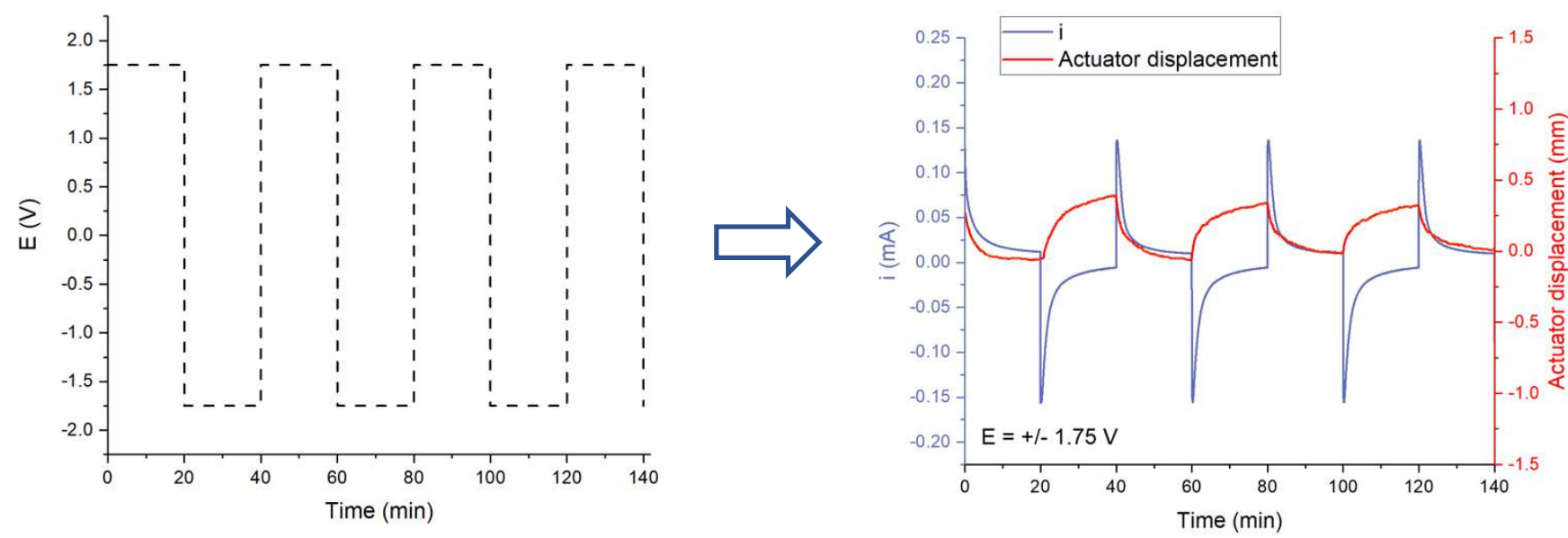

Figure 9: Left: square wave applied potential $( \pm 1.75 \mathrm{~V})$. Right: free displacement of actuators and current response. Displacement was measured at $\mathrm{L}=3 \mathrm{~mm}$ distance from clamped end 


\section{CONCLUSIONS AND FUTURE WORK}

This work reports the full fabrication of an all solid-state ionic actuator based on an electronic conducting polymer and polymeric ionic liquid. To the best of our knowledge it is the first time that this kind of actuators is reported in the literature. Although the proof of concept of this kind of actuators has been demonstrated these systems are much slower than classical conducting polymers-based actuators swelled in ionic liquids due to the lower value of ionic conductivities of PILs. So, in order to improve these performances and more specifically the actuation rates, diffusion speed must be increased by developing PIL with higher ionic conductivities and diffusion distances must be decreased by developing thinner devices as already demonstrated in the case of microactuators. It will be the focus of future works.

\section{REFERENCES}

[1] Shainpoor, M., "Ionic polymer-condctor composites as biomimetic sensors, robotic actuators and artificial muscles a review”, Electrochemica Acta, 48 (14-16), 2343-2353, (2003)

[2] Alici G., Devaud V., Renaud P. and Spinks G., "Conducting polymer microactuators operating in air" Journal of Micromechanics and Microengineering, 19 (2), 025017 (2009)

[3] Khaldi A., Plesse C., Soyer C., Cattan E., Vidal F., Legrand C., and Teyssié D., "Conducting interpenetrating polymer network sized to fabricate microactuators" Appl. Phys. Lett. 98, 164101 (2011)

[4] Wu Y., Alici G., Spinks G. M. and Wallace G., "Fast trilayer polypyrrole bending actuators for high speed applications" Synth. Met., 156, 1017-1022, (2006)

[5] Osada Y., Okuzaki H., Hori H., “A polymer gel with electrically driven mobility”, Nature, 355, 242-244, (1992)

[6] Okuzaki H., Takagi S., Hishiki F., Tanigawa R., "Ionic liquid/polyurethane/PEDOT:PSS composites for electroactive polymer actuators", Sensors and Actuators B, 194, 59-63, (2014)

[7] Gairhe B., Alici G., Spinks G. M., Cairney J. M., "Pushing the limits for microactuators based on electro-active polymers", Journal of microelectromechanical systems, 21 (3), 574-585, (2012)

[8] Smela E., "Microfabrication of PPy microactuators and other conjugated polymer devices", J. Micromech. Microeng., 9, 1-18, (1999)

[9] Roemer M., Kurzenknabe T., Oesterschulze E., Nicoloso N., "Microactuators based on conducting polymers", Analytical and Bioanalytical Chemistry, 373, 754-757, (2002)

[10] Maziz A., Plesse C., Soyer C., Chevrot C., Teyssie D., Cattan E., and Vidal F., "Demonstrating kHz Frequency Actuation for Conducting Polymer Microactuators", Advanced Functional Materials, 24 (30), 4851-4859, (2014)

[11] Holly L. Ricks-Laskoski and Arthur W. Snow, "Synthesis and Electric Field Actuation of an Ionic Liquid Polymer", Journal of American Chemical Society, 128 (38), 12402, (2006)

[12] Washiro S., Yoshizawa M., Nakajima H., Ohno H., "Highly ion conductive flexible films composed of network polymers based on polymerizable ionic liquids", Polymer, 45, 1577-1582, (2004)

[13] Huadong T., Jianbin T., Shijie D., Maciej R., Youqing H., "Atom Transfer Radical Polymerization of Styrenic Ionic Liquid Monomers and Carbon Dioxide Absorption of the Polymerized Ionic Liquids", Journal of Polymer Science: Part A: Polymer Chemistry, Vol. 43, 1432-1443 (2005)

[14] Nakajima H., Ohno H., "Preparation of thermally stable polymer electrolytes from imidazolium-type ionic liquid derivatives", Polymer, 46, 11499-11504, (2005)

[15] Dezhi Z., GeoffreyM. S., Gordon G. W., Churat T., Douglas R. M., Maria F., Jiazeng S., "Solid state actuators based on polypyrrole and polymer-in-ionic liquid electrolytes", Electrochimica Acta, 48, 2355, (2003) 
[16] McEwen A. B., Ngo H. L., LeCompte K., Goldman J. L., "Electrochemical properties of imidazolium salt electrolytes foe electrochemical applications", J. Electrochem. Soc., 146, 1687-1695, (1999)

[17] Nakagawa H., Izuchi S., Kuwana K., Nukuda T., Aihara Y., "Liquid and polymer gel electrolytes for lithium batteries composed of room-temperature molten salts doped by lithium salt", J. Electrochem. Soc., 150, 695-700, (2003)

[18] Doyle M., Choi S. K., Proulx G., "High-temperature proton conducting membranes based on perfluorinated ionomer membrane - Ionic liquid composites", J. Electrochem. Soc., 147, 34-37, (2000)

[19] Susan M.A.B.H., Noda A., Mitsushima S., Watanabe M., "Ion gels prepared by in situ radical polymerization of vinyl monomers in an ionic liquid and their characterization as polymer electrolytes", Journal of American Chemical Society., 127, 4976-4983, (2003)

[20] Ue M., Takeda M., Toriumi A., Kominato A., Hagiwara R., Ito Y., "Application of low-viscosity to the electrolyte of double-layer capacitors", J. Electrochem. Soc., 150, A499-A502, (2003)

[21] Wang P., Zakeeruddin S. M., Moser J. E., Nazeeruddin M. K., Sekiguchi T., Grätzel M., “A stable quasi-solid-state dye sensitized solar cell wth an amphiphilic ruthenium sensitizer and polymer gel electrolyte", Nature Materials, 2, $402-$ 407, (2003)

[22] Wang P., Zakeeruddin S. M., Comte P., Exnar I., Gratzel M., "Gelation of ionic liquid-based electrolytes with silica nanoparticles for quasi-solid-state dye-sensitized solar cells”, J. Am. Chem. Soc., 125 (5), 1166-1167, (2003)

[23] Winther-Jensen, B.; West, K., "Vapor-phase polymerization of 3,4-Ethylenedioxythiophene: A route to highly

conducting polymer surface layers", Macromolecules, 37, 4538-4543, (2004)

[24] Im, S. G.; Olivetti, E. A.; Gleason, K. K., "Systematic control of the electrical conductivity of poly(3,4ethylenedioxythiophene) via oxidative chemical vapor deposition", Macromolecules, 40 (18), 6552-6556, (2007)

[25] Sugino T., Kiyohara K., Takeuchi I., Mukai K., Asaka K., “Actuator properties of the complexes composed by carbon nanotube and ionic liquid: The effects of additives", Sensors and Actuators B, 141, 179-186, (2009)

[26] Lawal A. T., Wallace G. G., "Vapour phase polymerization of conducting and non-conducting polymers: a review", Talanta, 119, 133-143, (2014)

[27] Zhang X. G., Butler W. H., "Conductivity of metallic films and multilayers", Phys. Rev. B, 51, 10085-10103, (1995)

[28] Kim, J.; Sohn, D.; Sung, Y.; Kim, E.-R., "Fabrication and characterization of conductive polypyrrole thin film prepared by in situ vapor-phase polymerization", Synth. Met., 132, 309-313, (2003)

[29] Fabretto M., Autere J-P., Hoglinger D., Field S., Murphy P., "Vacuum vapour phase polymerized poly(3,4ethylenedioxythiophene) thin films for use in large-scale electrochromic devices", Thin solid films, 519, 2544-2549, (2011)

[30] Marcilla R., Ochoteco E., Pozo-Gonzalo C., Grande H., Pomposo J. A., Mecerreyes D., “New Organic Dispersions of Conducting Polymers Using Polymeric Ionic Liquids as Stabilizers", Macromolecular rapid communications, 26 (14), 1122-1126, (2005)

[31] Wang X., Shapiro B., Smela E., "Visualizing ion transport in conjugated polymers”, Adv. Mater., 16 (18), $1605-$ $1609,(2004)$

[32] Temmer R., Maziz A., Plesse C., Aabloo A., Vidal F., and Tamm T., "In search of better electroactive polymer actuator materials: PPy versus PEDOT versus PEDOT-PPy composites," Smart Mater. Struct., 22 (10), 104006, (2013) 